\title{
Effect of Low Energy Implantation on the Properties of Ti/Ni/Au Contacts to n-SiC
}

Patrick W Leech ${ }^{1}$, Anthony S Holland ${ }^{1}$, Geoffrey K Reeves ${ }^{1}$, Yue Pan ${ }^{1}$, Mark Ridgway ${ }^{2}$, Phillip Tanner $^{3}$

${ }^{1}$ School of Electrical and Computer Engineering, RMIT University, Melbourne, Victoria, 3001, Australia

${ }^{2}$ Electronic Materials Engineering, Australian National University, Canberra, ACT, Australia.

${ }^{3}$ Griffith University, Queensland Microtechnology Facility, Brisbane, Australia.

\begin{abstract}
The effect of low energy implantation of $\mathrm{P}$ or $\mathrm{C}$ ions in $3 \mathrm{C}-\mathrm{SiC}$ on the properties of $\mathrm{Ti} / \mathrm{Ni} / \mathrm{Au}$ contacts has been examined for doses in the range $10^{13}-10^{15} \mathrm{ions} / \mathrm{cm}^{2}$. Measurements of specific contact resistance, $\rho_{\mathrm{c}}$, were performed using the two-contact circular test structure. The magnitude of $\rho_{\mathrm{c}}$ for the Ti/Ni/Au contacts on unimplanted $\mathrm{SiC}$ was $1.29 \times 10^{-6} \Omega . \mathrm{cm}^{2}$. The value of $\rho_{c}$ increased significantly at an implant dose of $1 \times 10^{15} \mathrm{ions} / \mathrm{cm}^{2}$. The dependence of $\rho_{\mathrm{c}}$ on ion dose has been measured using both $\mathrm{C}$ and $\mathrm{P}$ implant species.
\end{abstract}

\section{INTRODUCTION}

The semiconductor $\mathrm{SiC}$ has shown exceptional properties in devices used in harsh environments such as at elevated temperatures and high power levels. Recent developments in the growth of high quality epitaxial layers of $3 \mathrm{C}$ and $6 \mathrm{H}-\mathrm{SiC}$ on $\mathrm{Si}$ substrates have enabled the large-scale fabrication of these devices. An important requirement in the realization of high power devices on $\mathrm{SiC}$ has been the ability to form ohmic contacts with characteristics of low resistivity and high thermally stability. The most commonly used ohmic contacts to $\mathrm{n}-\mathrm{SiC}$ have consisted of the deposition of a layer of metal ( $\mathrm{Ni}, \mathrm{Ti}, \mathrm{Co}, \mathrm{Pd}$ or Pt [1]) or carbon [2] followed by annealing at $\sim 1000{ }^{\circ} \mathrm{C}$. However, the high temperatures required for the localized formation of metal silicides or carbides at the interface has resulted in a degradation of the underlying $\mathrm{SiC}$ and a roughening of the metal surface [1]. Ion implantation has previously been used in the heavy doping of $\mathrm{SiC}$ below the contact although very high temperatures $\left(\sim 1500^{\circ} \mathrm{C}\right)$ have been required for activation [3]. An alternative method of modifying the interfacial properties of $\mathrm{SiC}$ without the use of heavy impurity doping and high temperatures has been the prior implantation with low energy ions. The bombardment of polycrystalline $\mathrm{SiC}$ with low energy Ar ions at 330, 450 and $540 \mathrm{eV}$ has been reported to reduce both the surface energy and internal stress within the layer [4]. In $\mathrm{Cr} / \mathrm{n}-\mathrm{SiC}$ contacts, Grodzicki et al. have shown a transition from a non-linear to a linear current/ voltage response following the bombardment of n-SiC with Ar ions at $1.2 \mathrm{keV} \mathrm{[5].}$

In this paper, we examine the effect of prior implantation of n-SiC with low energy ions on the electrical characteristics of $\mathrm{Ti} / \mathrm{Ni} / \mathrm{Au}$ contacts. Variation in the implant species (C and $\mathrm{P})$ and dose $\left(10^{13}-10^{15}\right.$ ions $\left./ \mathrm{cm}^{2}\right)$ were used in investigating for the first time the properties of these contacts. The interfacial layer of Ti was selected because of the ability of this metal to form ohmic contacts on $\mathrm{n}-\mathrm{SiC}$ at a relatively lower annealing temperature than alternative metals [7]. 


\section{EXPERIMENTAL DETAILS}

An epitaxial layer of n-type $3 \mathrm{C}-\mathrm{SiC}$ was grown on $10 \mathrm{~cm}$ wafers of $\mathrm{p}-\mathrm{Si}<100>$ by low pressure chemical vapor deposition (LPCVD) in a hot wall reactor [6]. The film of n-SiC was deposited to a thickness of $1.0 \mu \mathrm{m}$ with a carrier concentration of $1 \times 10^{18} \mathrm{~cm}^{-3}$. The wafers were diced into square pieces with dimensions of $1 \times 1 \mathrm{~cm}$. The layer of $\mathrm{SiC}$ was then implanted with either $\mathrm{C}$ or $\mathrm{P}$ ions at $-196{ }^{\circ} \mathrm{C}$ using an energy of $5 \mathrm{keV}$ and a dose in the range $10^{13}-10^{15}$ ions $/ \mathrm{cm}^{2}$. These two species were selected on the basis of calculations using the TRIM (transport and range of ions in matter) code which have predicted distinctly different profiles of energy deposition for $\mathrm{P}$ and $\mathrm{C}$ ions in $\mathrm{SiC}$. An array of two-contact circular test patterns [7] was then fabricated on the surface of the implanted $\mathrm{SiC}$ by a standard process of lift-off. A layer of AZ1512 resist was initially spin-coated onto the surface of the SiC followed by lithographic patterning into a two contact circular test structure [7]. Prior to the deposition of metal layers, the patterned samples were dipped in a solution of buffered $10 \%$ HF for $15 \mathrm{sec}$ and rinsed in deionised water. Sequential layers of Ti $(50 \mathrm{~nm}) / \mathrm{Ni}(50 \mathrm{~nm}) / \mathrm{Au}(100 \mathrm{~nm})$ were then deposited by electron beam evaporation onto the $\mathrm{n}$-SiC layer. As illustrated in Fig. 1, the radius of the central circular contact, $\mathrm{r}_{0}$, was varied from $4.25-10.25 \mu \mathrm{m}$ which corresponded to a gap spacing between the inner circular and outer ring electrodes of $1.5-7.5 \mu \mathrm{m}$. The terms $r_{1}$ and $r_{1}^{\prime}$ have been used to define the inner and outer radii of the ring electrode. The values of $r_{1}$ and $r_{1}^{\prime}$ were held constant for each of the patterns in Fig.1 while varying the radius of the inner electrode. The specific contact resistance, $\rho_{\mathrm{c}}$, of the ohmic contacts was measured by probing of the circular test patterns. The sheet resistance, $\mathrm{R}_{\mathrm{sh}}$, of the $\mathrm{SiC}$ was determined by a four point probe technique.
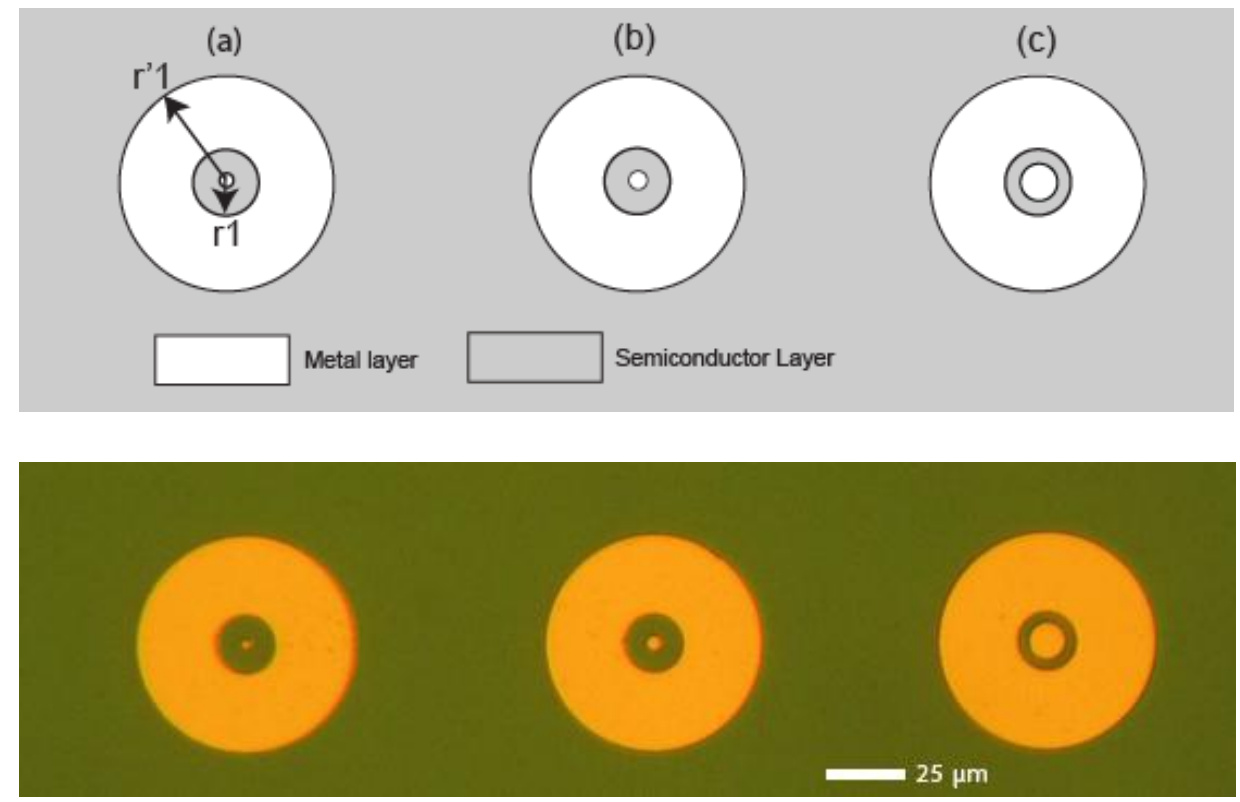

Figure 1. Electrode pattern based on the two-contact circular test structure [7] used in the measurement of specific contact resistance. The spacing in the gap between the inner circular and outer ring electrodes was (a) $7.5 \mu \mathrm{m}$, (b) $4.5 \mu \mathrm{m}$ and (c) $1.5 \mu \mathrm{m}$. 


\section{RESULTS AND DISCUSSION}

Figs. 2(a) and (b) show TRIM (Transport of Radiation In Matter) simulations of a) the concentration of $\mathrm{P}$ and $\mathrm{C}$ ions versus depth and $\mathrm{b}$ ) the distribution of energy deposition resulting from an implantation at $5 \mathrm{keV}$ into $\mathrm{SiC}$. The TRIM code has simulated the cumulative effects of individual ions in their collisions through the substrate. In Fig. 2(a), the implanted P ions have exhibited a higher level of peak concentration than for the $\mathrm{C}$ ions. Also, the peak in $\mathrm{P}$ concentration in Fig. 2(a) was evident at a shallower depth $(5-10 \mathrm{~nm})$ than the maximum level of $\mathrm{C}$ which was located at 10-15 nm below the surface. Fig. 2(b) shows that the distribution of energy deposition was similar in profile to the ion concentration versus depth in Fig. 2(a). However, the plots in Fig. 2(b) have predicted a slightly shallower depth for the maximum peak than the equivalent value as evident in Fig. 2(a). In Fig. 2(b), the peak in energy deposition was located at $5 \mathrm{~nm}$ for $\mathrm{P}$ ions and 5-10 $\mathrm{nm}$ for C. The TRIM simulations have also predicted a linear increase in both the concentration of implanted $\mathrm{P}$ or $\mathrm{C}$ ions and the energy deposition with dose. Figs. 2(a) and (b) were plotted using a dose of $1 \times 10^{15}$ ions $/ \mathrm{cm}^{2}$.

Fig. 3 shows plots of current (I) versus voltage (V) for Ti/Ni/Au contacts on both the unimplanted and ion implanted $\mathrm{SiC}$. For the unimplanted samples, the I/V response was ohmic with a relatively low resistance. For each of the $\mathrm{C}$ and $\mathrm{P}$ implants, Fig. 3(a) and (b) also show that I/V plots were linear with a decrease in slope or increase in the resistance of the Ti/ $\mathrm{Ni} / \mathrm{Au}$ contacts with increase in implant dose. The measurements of $\rho_{\mathrm{c}}$ versus implant dose for Ti/Ni/Au contacts have been plotted in Fig. 4. For the unimplanted $\mathrm{SiC}$, the value of $\rho_{\mathrm{c}}$ was measured as $1.29 \times 10^{-6} \Omega . \mathrm{cm}^{2}$. With prior implantation at doses of $1 \times 10^{13}$ and $1 \times 10^{14} \mathrm{C}$ ions $/ \mathrm{cm}^{2}$, the magnitude of $\rho_{c}$ was greater by a factor of $\sim 2$ than the value for the unimplanted SiC. In Fig. 4 , a steep rise in $\rho_{\mathrm{c}}$ was evident only at an implant dose of $1 \times 10^{15} \mathrm{C}$ ions $/ \mathrm{cm}^{2}$. The implantation with $\mathrm{C}$ ions at $1 \times 10^{15} \mathrm{C}$ ions $/ \mathrm{cm}^{2}$ has resulted in a higher value of $\rho_{c}=1.8 \times 10^{-4} \Omega . \mathrm{cm}^{2}$ than for $\mathrm{P}$ implants at this dose for which $\rho_{\mathrm{c}}=4.1 \times 10^{-5} \Omega . \mathrm{cm}^{2}$.
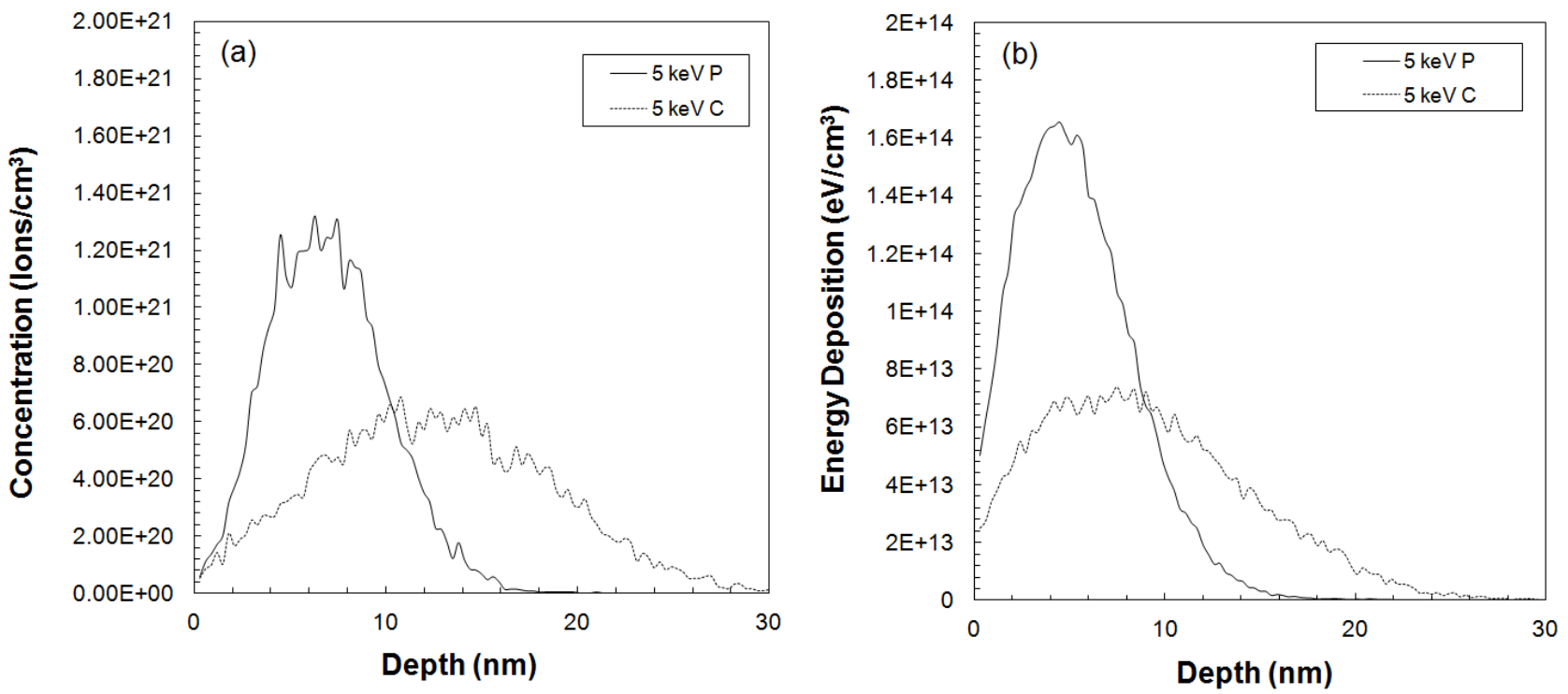

Figure 2. TRIM simulation of (a) $\mathrm{P}$ and $\mathrm{C}$ ion concentration and b) the distribution of energy deposition after implantation into $\mathrm{SiC}$ at $5 \mathrm{keV}$ at a dose of $1 \times 10^{15} \mathrm{ions} / \mathrm{cm}^{2}$. 

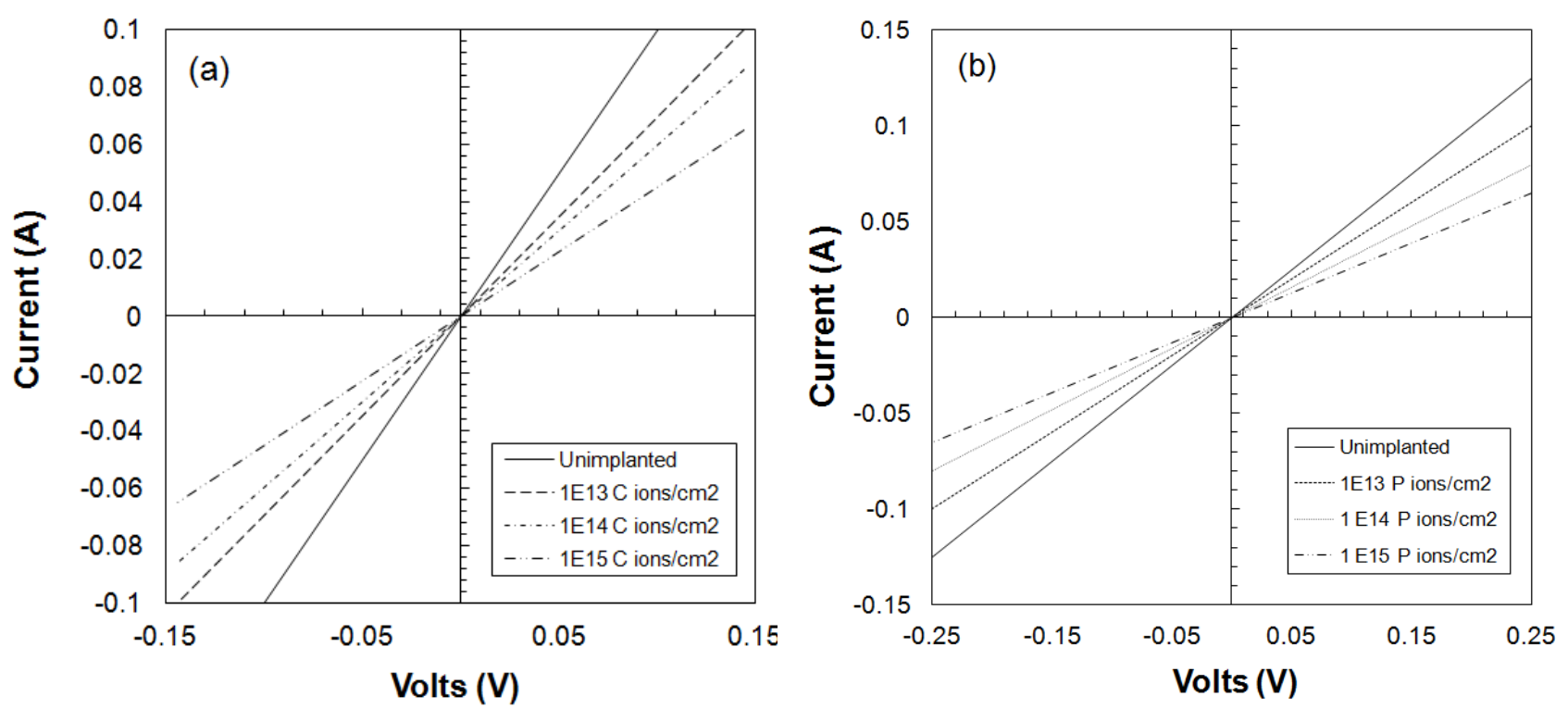

Figure 3. Plots of I/V characteristics for $\mathrm{Ti} / \mathrm{Ni} / \mathrm{Au}$ contacts on unimplanted $\mathrm{SiC}$ and after implantation with either a) $\mathrm{C}$ or b) $\mathrm{P}$ ions at doses of $1 \times 10^{13}-1 \times 10^{15}$ ions $/ \mathrm{cm}^{2}$.

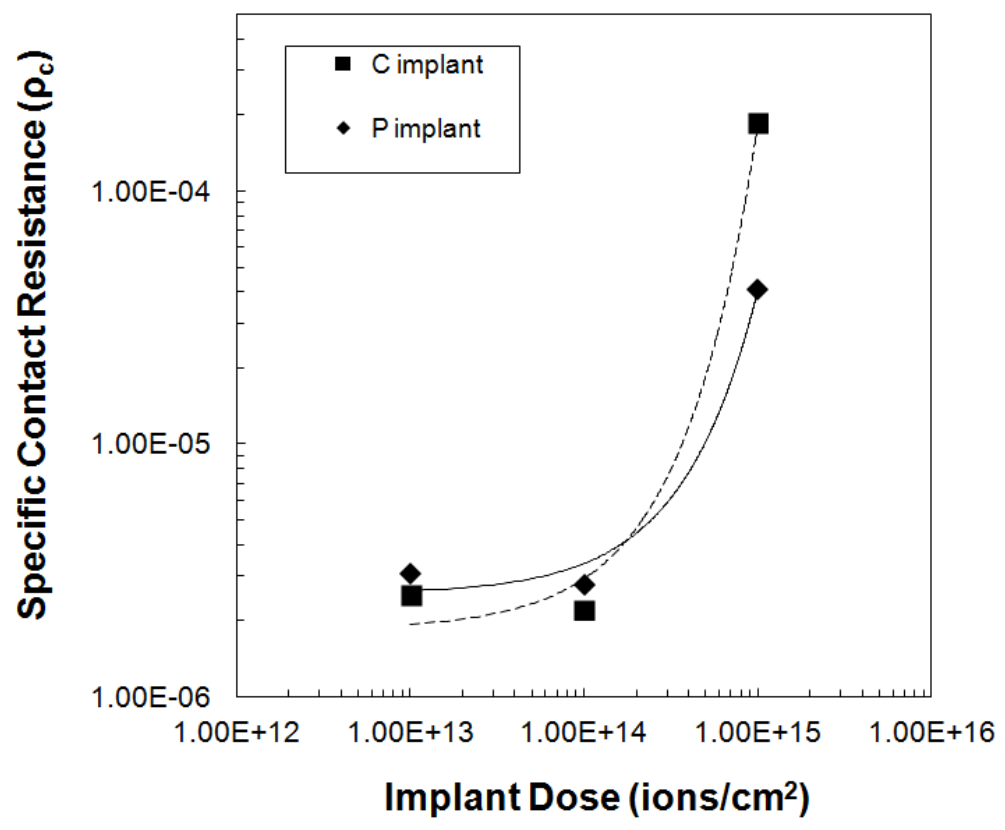

Figure 4. Specific contact resistance, $\rho_{\mathrm{c}}$, versus dose for $\mathrm{Ti} / \mathrm{Ni} / \mathrm{Au}$ contacts to $\mathrm{SiC}$ implanted with $\mathrm{P}$ or $\mathrm{C}$ ions at $5 \mathrm{keV}$. 
Figure 5 shows measurements of $\mathrm{R}_{\text {sh }}$ plotted as a function of implant dose. The average value of $\mathrm{R}_{\mathrm{sh}}$ for the unimplanted samples was measured as $26.5 \Omega / \mathrm{sq}$. Fig. 5 shows that the implantation of the $\mathrm{SiC}$ with $\mathrm{C}$ ions at a dose of $1 \times 10^{13}$ ions $/ \mathrm{cm}^{2}$ has resulted in only a small increase in $\mathrm{R}_{\mathrm{sh}}$. However, the implantation at higher doses of $1 \times 10^{14}$ and $1 \times 10^{15} \mathrm{C}$ ions $/ \mathrm{cm}^{2}$ has resulted in a sharp rise in $\mathrm{R}_{\mathrm{sh}}$. In comparison, the implantation of $\mathrm{SiC}$ with $\mathrm{P}$ ions has resulted in negligible change in $\mathrm{R}_{\text {sh }}$ for surfaces implanted with lower doses and a significant increase at 1 $\mathrm{x} 10^{15} \mathrm{P}$ ions $/ \mathrm{cm}^{2}$. Fig. 5 shows that the increase in $\mathrm{R}_{\mathrm{sh}}$ with dose was greater in magnitude for $\mathrm{C}$ ion implants than with an equivalent dose of $\mathrm{P}$ ions. The trends in both Figs. 4 and 5 have indicated that the deeper penetration of the lower mass $\mathrm{C}$ ions into $\mathrm{SiC}$ had a greater effect in increasing both $R_{s h}$ and $\rho_{c}$ than the shallower damage generated by the higher mass $P$ ions. The similarity between the effects of dose on $R_{\text {sh }}$ below the contact interface and $\rho_{c}$ was consistent with the direct dependence of $\rho_{\mathrm{c}}$ on $\mathrm{R}_{\mathrm{sh}}$ within the model for the two-contact circular test structure [7].

Previous studies of the damage induced by $\mathrm{P}$ implantation in $3 \mathrm{C}-\mathrm{SiC}$ by Song et al. have reported the formation of dislocation loops following the implantation with $\mathrm{P}$ ions at 20-250 keV [8] and similarly in 4H-SiC [9]. In addition, Kameda et al. have identified four types of damage after low energy (20 keV) implantation of $6 \mathrm{H}-\mathrm{SiC}$ [10] with nitrogen. Below dpa of 0.004, a negligible level of damage was evident in the crystal structure, a dpa in the range 0.004 to $\sim 0.01$ resulted in the extensive formation of defect structures and damage to the lattice, at 0.01 to $\sim 0.8$ an amorphous structure was formed and at dpa $\geq 0.8$, void formation was present. These levels of damage were almost certainly formed at a higher levels of dpa for $\mathrm{P}$ implants due to the higher atomic mass of the implanted species. Based on the measurements of $R_{\text {sh }}$ and $\rho_{c}$ in Figs. 4 and 5, the results in the present paper may be intepreted as located in zones i) or ii).

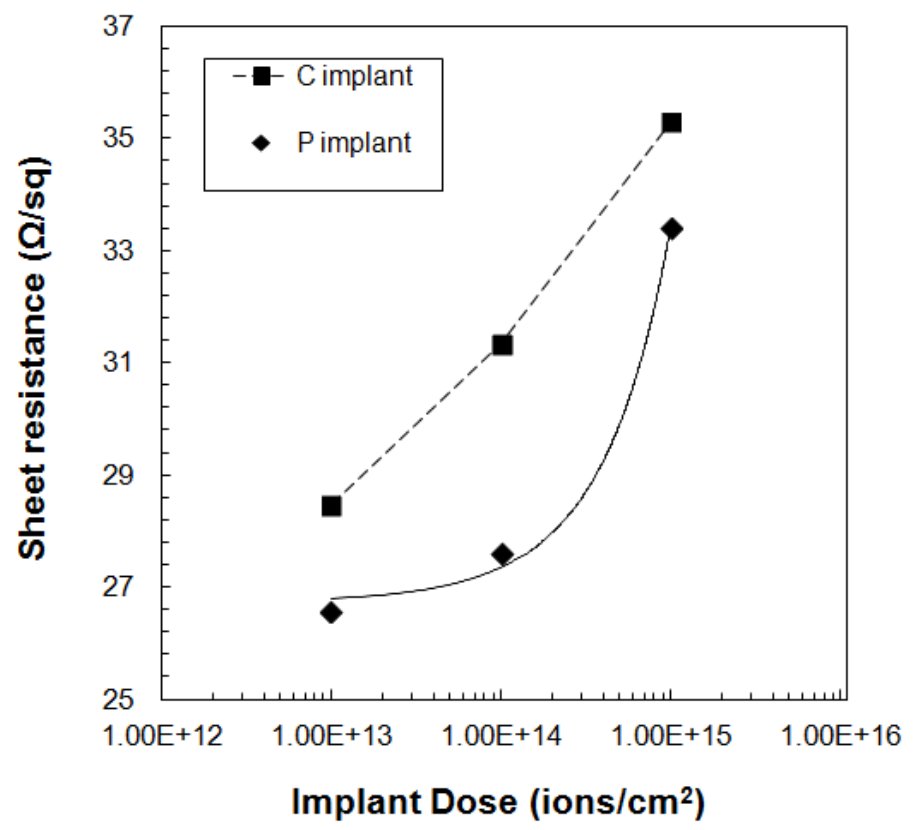

Figure 5. Sheet resistance, $\mathrm{R}_{\mathrm{sh}}$, versus implant dose for $\mathrm{P}$ and $\mathrm{C}$ ions at $5 \mathrm{keV}$. 
These two levels of damage were consistent with i) the low dose region characterised by little change in $R_{s h}$ and $\rho_{c}$ and ii) the higher dose region $\left(\geq 1 \times 10^{15}\right.$ ions $\left./ \mathrm{cm}^{2}\right)$ which was accompanied by a sharp increase in both $\mathrm{R}_{\mathrm{sh}}$ and $\rho_{\mathrm{c}}$. The implantations in SiC used in previous studies have been performed at a higher energy than the $5 \mathrm{keV}$ in the present work. However, the equivalence of ion concentration has allowed some comparison of the results. Future work will examine the annealing properties of the implanted $\mathrm{Ti} / \mathrm{Ni} / \mathrm{Au}$ contacts.

\section{CONCLUSIONS}

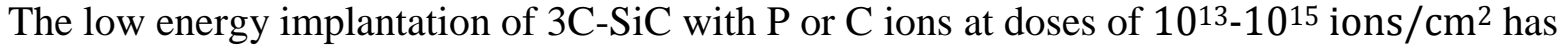
resulted in an increase in specific contact resistance, $\rho_{c}$, of Ti/Ni/Au contacts. A sharp increase in $\rho_{c}$ was evident an implant dose of $1 \times 10^{15}$ ions $/ \mathrm{cm}^{2}$. This trend in $\rho_{c}$, has correlated with a rise in sheet resistance, $\mathrm{R}_{\mathrm{sh}}$, of $\mathrm{SiC}$ with increase in implant dose. The implantation of $\mathrm{SiC}$ with $\mathrm{C}$ ions has resulted in higher values of $\rho_{\mathrm{c}}$ and $R_{\text {sh }}$ at each dose than with the equivalent implants using $\mathrm{P}$ ions.

\section{REFERENCES}

1. W. Lu, W.E. Collins, W.C. Mitchel in SiC Power Materials, Springer, Ed. Z.C. Chen (2004).

2. R. R. Leiten et al., Appl. Phys. Lett., 92, 022106 (2008).

3. G. Hui, Z. Yi-Men, Z. Yu-Ming, Chinese Physics, 15(9), 2142 (2006).

4. F. Liu, C.H. Li, A.P. Pisano, C. Carraro, R. Maboudia, JVSTA, A28, 1259 (2010).

5. M. Grodzicki, J. Chrzanowski, P. Mazur, S. Zuber, A. Ciszewski, Optica Applicata, 39(4), 765 (2009).

6. L. Wang, S. Dimitrijev, J. Han, F. Iocopi, L. Hold, P. Tanner, H.B. Harrison, Thin Solid Films, 5196443 (2011).

7. Y. Pan, G. K. Reeves, P. W. Leech, A. S. Holland, IEEE Trans. Electron Devices, 60, 1202 , (2013).

8. X. Song, J. Biscarrat, J-F. Michaud, F. Cayrel, M. Zielinksi, T. Chassagne, M. Portail, E, Collard, D. Alquier, Nucl. Instr. Meth. Phys. Res. B269 2020 (2011).

9. L. Chunjuan, L. Su, F. Jingjing, W. Rong, Journal of Semiconductors, 33(3) 036002-1 (2012).

10. T. Takeda, A. Tomita, T. Matsui, T. Isshiki, Materials Science Forum, 778-780, 350 (2014). 